\title{
Creating Knowledge Environment during Lean Product Development Process of Jet Engine
}

\author{
Zehra C. Araci ${ }^{1}$, Muhammad Usman Tariq ${ }^{3}$ \\ Abu Dhabi School of Management \\ Abu Dhabi, UAE
}

\author{
Ahmed Al-Ashaab ${ }^{2}$ \\ Cranfield University \\ Cranfield, UK
}

\author{
Jan H. Braasch ${ }^{4}$ \\ Dubai Airports \\ Dubai, UAE
}

\author{
M. C. Emre Simsekler ${ }^{5}$ \\ Department of Industrial and Systems Engineering \\ Department, Khalifa University of Science and Technology \\ Abu Dhabi, UAE
}

\begin{abstract}
Organizations invest intense resources in their product development processes. This paper aims to create a knowledge environment using trade-off curves during the early stages of the set-based concurrent engineering (SBCE) process of an aircraft jet engine for a reduced noise level at takeoff. Data is collected from a range of products in the same family as the jet engine. Knowledge-based trade-off curves are used as a methodology to create and visualize knowledge from the collected data. Findings showed that this method provides designers with enough confidence to identify a set of design solutions during the SBCE applications.
\end{abstract}

Keywords-Knowledge creation and visualization; knowledge management; new product development; lean product development; set-based concurrent engineering; trade-off curves; aircraft engine noise reduction

\section{INTRODUCTION}

Due to rapid technological changes, organizations are under pressure to be agile enough in order to respond to the fast-changing demand [8]. This agility can be gained by improving its product development activities. However, designers face several challenges, especially during the early stages of developing a new product [1]. These challenges could be addressed by the lean product development (LeanPD) approach [22]. During the LeanPD process, it is essential to have the right knowledge environment in order to achieve a robust optimal design [27]. Trade-off curves (ToCs) provide this environment by creating and visualizing the knowledge that is based on the physical insights of the product as well as experienced data (e.g., outcomes of R\&D, data from successful or failed projects) [13].

There are several challenges that the manufacturing industry faces during their product development processes [26]. Some of these challenges are reworking, late design changes, communication challenges between departments, and, most importantly, lack of knowledge [15]. Having the right knowledge environment supports designers or product developers to increase the project success rate, to reduce rework during product development, and to reduce manufacturing costs that are caused by inaccurate design solutions [4]. In order to create such a knowledge environment, trade-off curves are effective LeanPD tools to be used throughout the product development processes [3].

Trade-off curves are primarily used by Wright Brothers, who succeeded in operating an aircraft for the first time [13]. Air transportation has gained significant popularity, and the form of aircraft considerably improved since then. The efficiency of aircraft production has increased due to technology changes. But most importantly, because of the knowledge-gained throughout all these years [9]. On account of the developments, recently, many international and even domestic flights are preferred as an alternative means of transportation compared to road transport [10]. However, this new habit causes challenges from environmental aspects such as high noise levels [2]. Environmental concerns and statutory regulations push airlines to operate low noise aircraft at takeoff, especially during the night flights [16]. The jet engine is known as the major source of an aircraft noise [17]. Although there are studies on reducing the jet engine noise, there is limited progress achieved so far [18].

This paper aims to create an initial knowledge environment for designers by using trade-off curves in order to identify a set of possible design solutions from the previous projects of an aircraft jet engine [19]. Having such a designset provides designers with sufficient knowledge during the SBCE applications of achieving a final optimized solution, which is expected to have the lowest noise level available in the market [2].

This paper consists of different research steps. First, the authors reviewed the literature to identify the role of trade-off curves within SBCE processes and to identify the possible causes of the high noise levels in an aircraft engine, specifically civil aircraft. The literature review findings are presented in Section 2. After the literature review, the authors conducted a case study of a family of civil aircraft jet engines as presented in Section 3. Publicly available data was collected and reflected on the form of trade-off curves by using the process of generating trade-off curves [3]. Finally, analysis of the trade-off curves supported authors in developing a set of possible design solutions to be used in the SBCE process. Further stages of the SBCE applications are 
not the scope of this paper. Following the case study, discussion, and future work are presented in Section 4, and the research is concluded in Section 5.

\section{LITERATURE REVIEW}

\section{A. Trade-off Curves within SBCE Concept}

Open, global markets have been a key driver of growth and profit for manufacturing companies over the last 75 years. This trend can be expected to continue despite recent political developments in some countries. However, with access to international means of production and markets also comes international competition [4]. Combined with the increasing digitalization that lowers entry barriers, this has created pressure on companies to provide high-quality products and services in an environment of often rapidly changing demand. This need for flexibility and short time-to-market timeframes makes an efficient product development (PD) process a key success factor [29]. Demand cycles, especially in consumer markets, are now often characterized by extremely short durations while, at the same time, carrying huge revenue potentials. Sustaining market share (or even improving) it depends on the timely development of products that service this short-lived demand, and companies with such capabilities have a distinctive, differentiating competitive advantage. Efficient PD capabilities rely on several management systems, tools, and techniques that allow companies to leverage organizational knowledge and continuously improve processes [21]. For companies, the efficient development of new products, as well as access to organizational knowledge, have become important assets [30].

In more recent times, Toyota has used trade-off curves as a knowledge visualization tool in order to facilitate their SBCE application [25]. There, trade-off curves are part of "jidoka," which refers to a visual management technique that Toyota integrated into their PD process from lean manufacturing [20]. Now, they visually display subsystem knowledge in a graph so that engineers can explore the design space [31] and evaluate design alternatives [14]. Moreover, in a lean product development context, trade-off curves avoid the reinvention of previously considered design solutions during prototyping [32]. Hence, engineers save time that they can spend on new and innovative solutions [11].

Previous research exhaustively demonstrated how tradeoff curves could be generated and utilized throughout the stages of set-based concurrent engineering [4]. This paper aims to show an application of trade-off curves in the early stage of the design of a complex product, which is a turbofan jet engine [1].

\section{B. Civil Aircraft Noise Challenge}

Aircraft noise is a significant issue, and it has a direct effect on human hearing [6]. It is a well-established fact that it can cause hearing problems in humans [7]. Unwanted noise can create problems that can distract communication, reduce the quality of communication, and increases stress. Aircraft noise compatibility has been a serious issue that reduced the growth of commercial aviation [12]. Already several European airports have reached their maximum environmental load capacity before starting the use of runway and other infrastructure. One of the important challenges faced by environmental management authorities and the advisory council for Aeronautics research is to reduce the current noise of aircraft by $50 \%$ (-10db/operation). Different solutions have been tested to control the overall noise at airports. However, the noise in the surroundings of the airports has been trouble and remains high at takeoff and landing time [7].

\section{Work Principles of a Turbofan Jet Engine}

A review of the related literature showed that certain parameters influence the reduction of takeoff noise. Additionally, understanding the physical/technical details about a jet engine facilitated identifying parameters to focus on [28]. A jet engine is a key component of most modern aircraft, as it provides, by jet propulsion, required to reach speeds that enable heavier-than-air flight. The jet engine's most common form is the turbofan engine [23]. A propulsive force is generated by accelerating the entering gas (air) between the entrance and the exit of the engine [24]. The "General Thrust Equation" defines thrust as the difference between the product of mass flow at the exit ( $m e$ ) and the gas speed differential between exit and entry $(V e-V 0)$, and the product of mass flow at the entrance $(m 0)$ and the gas speed differential $(V e-V 0)$. By definition, all air entering the engine must also leave it, from which follows that $m e=m 0$ at all times.

General Thrust Equation:

FThrust $=m \mathrm{e}(V e-V 0)-m 0(V e-V 0)$

The essence of the General Thrust Equation is that additional thrust can be generated in two ways:

1) Increasing the mass flow rate $m e=m 0$

2) Increasing the speed differential of the gas $(V e-V 0)$

\section{CASE Study: JET Engine Noise Reduction}

\section{A. Customer and Design Requirements}

The knowledge is gained through the literature review and technical aspect of the product, as mentioned above. Based on this knowledge, the authors defined essential requirements as decision criteria:

1) Low noise: The takeoff noise level of the new product should be lower than the noise levels of existing products.

2) Reliability: The new product should operate $24 / 7$ without significant downtime.

3) Durability: The new product should be durable enough to be able to operate on an aircraft capable of carrying 150 passengers. As all aircraft must be able to fly with only half their engines operating, each engine on a twin-engine aircraft must be capable of carrying all passengers.

4) Cost: Fuel consumption should not be higher than the consumption of existing turbofan jet engine solutions.

In order to visualize the requirements by using trade-off curves, the authors also identified the parameters related to the requirements as follows: Take-off noise, maximum takeoff mass (MOTM), bypass ratio, and thrust. Table I displays the parameters and their conflicting relationships based on experts' opinions. 


\section{B. Key Design Parameters}

Data for the identified parameters were collected from publicly available sources. Fifty-five different types of jet engines are demonstrated in the trade-off curves in this section. It is worth to mention that the collected data set is real and experienced from successfully finished projects rather than computer-generated data.

Trade-off curves were generated by using Minitab as analysis software. Data analysis has been performed in order to see the correlations between the different parameters, as indicated in Table I.

\section{Takeoff Noise vs. Thrust, Bypass Ratio, MTOM}

The metric for takeoff noise level is EPNdB, which means effective perceived noise in decibel, and the metric for thrust is defined as newton $(\mathrm{N})$. Fig. 1 shows a positive correlation between the noise and thrust, which means that higher thrust causes higher takeoff noise. However, there is one design solution found with a high thrust $(284,500 \mathrm{~N})$ but relatively low noise (90.1 EPNdb) compared to other design solutions.

Simply, bypass ratio is the mass flow of air going into the engine core and burnt divided by the mass flow of air going around the engine core and exiting the engine as it is [5]. For example, a bypass ratio of 10:1 means that 11 units of air are drawn into the engine, ten units go around (bypass) the engine core and exit, but 1 unit goes through the engine core and burn. A high bypass ratio is a desirable factor in this case as it is believed that high bypass ratio results with a low noise engine. However, when we analyzed the data for bypass ratio and takeoff noise in Fig. 2, it was found that there is no significant relationship between these two parameters. A design solution has been defined with a high bypass ratio but relatively low takeoff noise.

TABLE I. CONFLICTING RELATIONSHIPS BETWEEN THE DESIGN PARAMETERS OF A LOW NOISE JET ENGINE

\begin{tabular}{|l|l|l|}
\hline No. & $\begin{array}{l}\text { Parameters and } \\
\text { Relationships }\end{array}$ & Conflicts between the design parameters \\
\hline 1 & $\begin{array}{l}\text { Thrust vs. Takeoff } \\
\text { Noise Level }\end{array}$ & $\begin{array}{l}\text { Engine noise was defined as 100\% of the } \\
\text { aircraft takeoff noise. As aircraft take off } \\
\text { with full power, thrust and fuel consumption } \\
\text { are at a maximum. It was surmised that the } \\
\text { noise level is related to the amount of thrust } \\
\text { generated. }\end{array}$ \\
\hline 2 & $\begin{array}{l}\text { Bypass Ratio vs. } \\
\text { Takeoff Noise Level } \\
\text { the bypass ratio of the engine can be } \\
\text { increased. In order to increase the bypass } \\
\text { ratio, the fan diameter should be increased so } \\
\text { that the air intake increases. However, a } \\
\text { larger fan results in the engine being heavier, } \\
\text { and this leads to a higher bypass ratio with a } \\
\text { higher thrust but heavier aircraft. } \\
\text { Consequently, the possibility of reducing } \\
\text { aircraft engine noise becomes challenging. }\end{array}$ \\
\hline $\begin{array}{l}\text { Maximum Takeoff } \\
\text { Takeoff Noise Level }\end{array}$ & $\begin{array}{l}\text { As mentioned above, in general, larger and } \\
\text { heavier aircraft produce more noise than } \\
\text { lighter aircraft. By increasing the bypass ratio } \\
\text { by increasing the fan diameter, the engine } \\
\text { weight will also increase, which will increase } \\
\text { the MTOM. }\end{array}$ \\
\hline
\end{tabular}

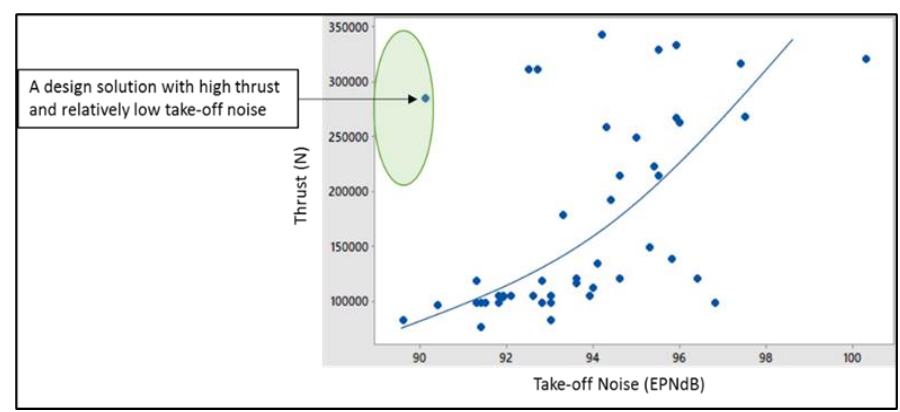

Fig. 1. Correlations between Takeoff Noise and Thrust.

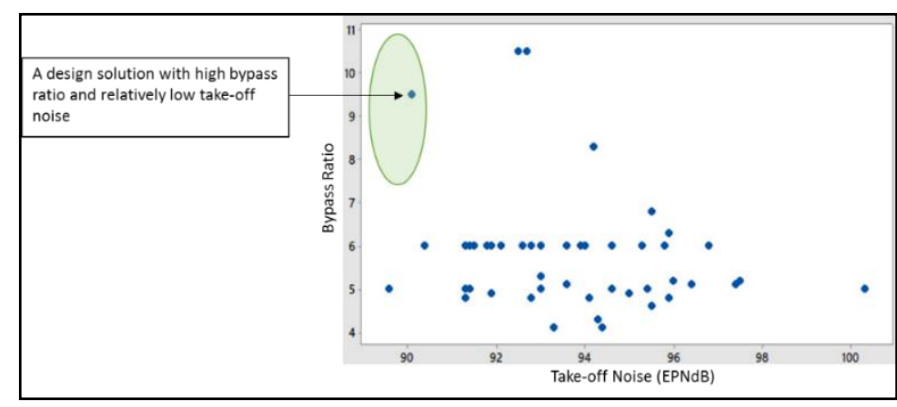

Fig. 2. Correlations between Takeoff Noise and Bypass Ratio.

Three-dimensional trade-off curve has been generated in order to understand if all these three parameters are related to each other; and, consequently, whether they are giving the same feasible design solution. As shown in Fig. 3, it was found that one engine has the potential to be considered within the design set in the early stage of product development. Further discussions are provided in the following section.

The authors carried some more investigations to understand the relationships between takeoff noise, thrust, and maximum takeoff mass (MTOM). MTOM is the weight of the aircraft in $\mathrm{kg}$ with an assumption that it operates full capacity (passengers and fuel). Fig. 4 shows that there is a strong positive relationship between thrust and maximum takeoff mass, which eventually means heavier aircraft requires more thrust than light aircraft. The effect of MTOM on takeoff noise has been investigated and displayed in Fig. 5 as a threedimensional trade-off curve. It appears that MTOM does not have a significant impact on the noise; however, it may facilitate noise reduction indirectly. The next section provides more details about the findings and discussions.

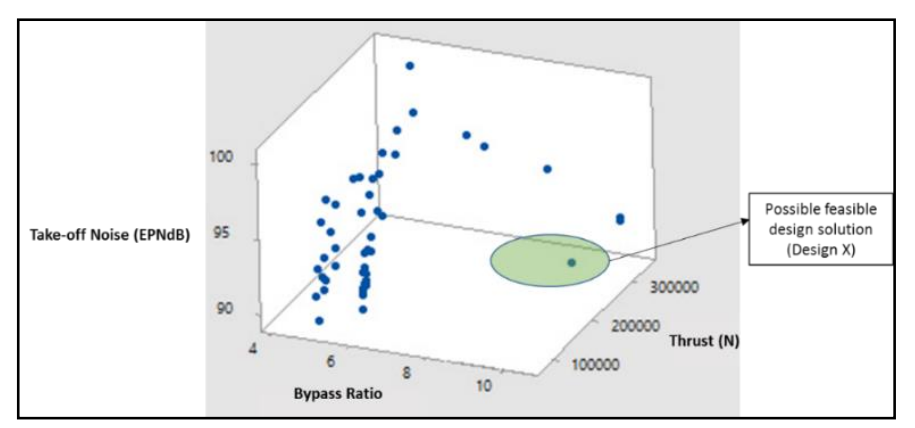

Fig. 3. Correlations between Takeoff Noise, Thrust and Bypass Ratio. 


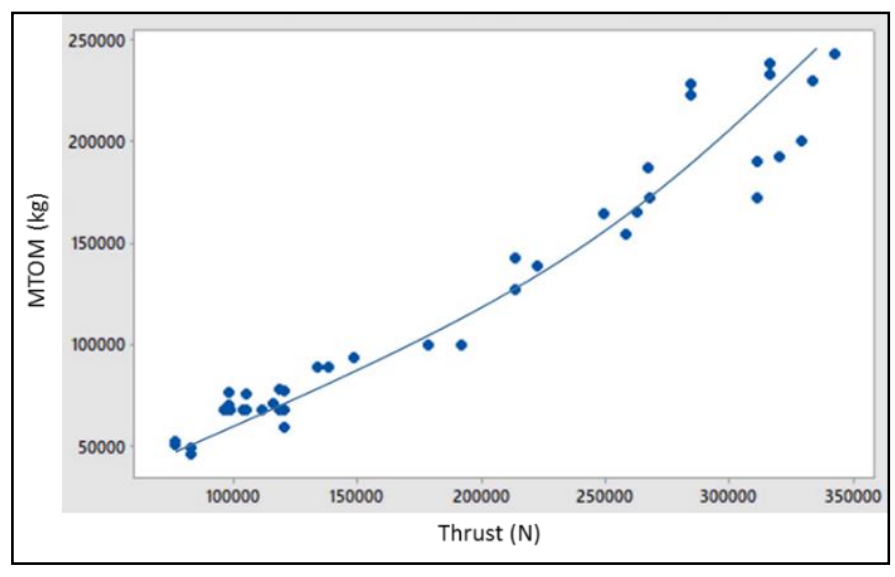

Fig. 4. Correlations between Thrust and MTOM.

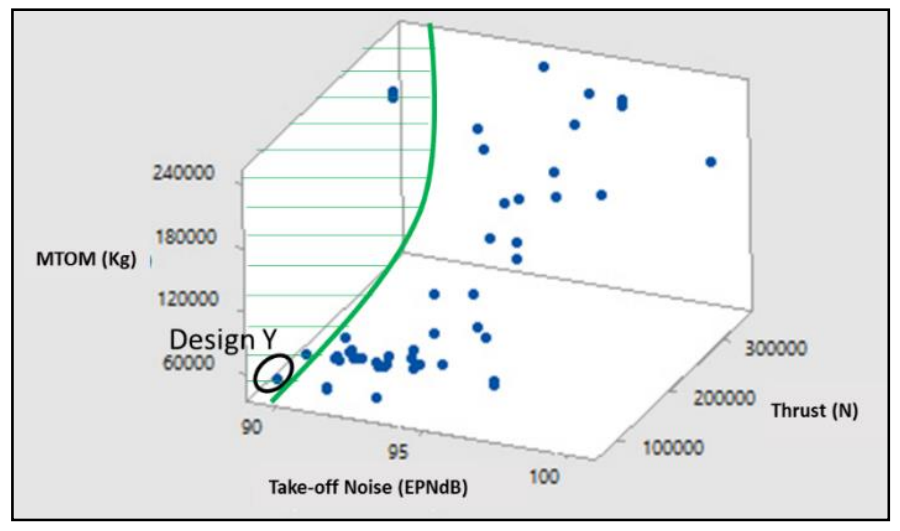

Fig. 5. Correlations between Takeoff Noise, Thrust, and MTOM.

\section{A Set of Possible Design Solutions}

After analysis of trade-off curves and as illustrated in Fig. 3 and 5, two design solutions (Design $\mathrm{X}$ and Design $\mathrm{Y}$ ) are selected in order to evaluate whether they are eligible to be considered within the design set. Selected design solutions were investigated, and the data of these designs were analyzed. It was determined that some designs might be used to create new, potentially feasible designs by combining several characteristics from several existing designs. In order to be a potentially feasible solution, existing designs might need to undergo one of the following actions: (1) Minor modifications, (2) Major modifications, and (3) Complete redesign.

\section{FInDINGS AND Discussion}

After the authors focused on the data that shows the lowest takeoff noise level, which is 90.6 EPNdB for Design X. Then, noise-related vital features and characteristics of Design $X$ have been investigated. Characteristic features of Design $\mathrm{X}$ are:

- Ultra-efficient, swept fan blades enable the quieter operation and optimal engine core protection.

- Full takeoff power is $3 \mathrm{~dB}$ quieter than the previous generation engine.
While it was understood from the ToCs that Design $\mathrm{X}$ could not be used as a whole system concept, the fan design might be an inspiring idea for a new design solution.

On the other hand, the authors focused on the data that shows the lightest engine with low noise in Fig. 5 (Design Y). A characteristic feature of Design $\mathrm{Y}$ is that it has a lightweight, hollow titanium wide chord fan for low noise and high efficiency. If the same material used in Design Y can also be used in a new design, this might decrease the engine weight of the new product design. Design $\mathrm{Y}$ engines power the Airbus A340 aircraft. This aircraft is configured with four engines. Four engines will be noisier than two engines. Besides, the total weight of an aircraft with four engines would be higher than an aircraft with two engines. Heavier aircraft also emit more noise. Therefore, Design Y could be reused if the fan diameter is increased (which reduces engine noise), and the number of engines is reduced from four to two. Furthermore, the passenger capacity of Design $\mathrm{Y}$ is more than 300 passengers, which is more than the customer requirement for passenger capacity in this study (150 passengers). Hence, it can be investigated if noise decreases when the Design Y engine is simulated for 150 passenger capacity.

Two design solutions, Design $\mathrm{X}$ and Design $\mathrm{Y}$, can be considered as the basis of future designs. As explained above, a combination of their characteristics may lead to the emergence of a viable solution that meets customer requirements. Converting these designs to a useful solution requires the use of the SBCE process model, which is not the scope of this paper but can be considered as future work. Several variables have an impact on the noise level of a jet engine. Due to the available data and sources, only four variables were investigated in this research. Fan diameter might be another key design parameter to be investigated in the future.

\section{ConClusion}

Previous projects - successful or failed - are vital elements of the intellectual capital of an organization. It is inevitable that the right knowledge environment, based on real data, supports designers' decision-making throughout their product development activities. Utilizing trade-off curves creates such a knowledge environment. This paper demonstrated an application of trade-off curves, how to create an initial right knowledge environment at the very early stages of the product development of an aircraft jet engine. Without any prototyping or investing great resources, two feasible design solutions out of 55 were suggested for further investigation. The existing design solutions Design X and Design Y can be considered hypothetically to be reused, after modifications, in order to develop a design-set for the set-based concurrent engineering application of a low noise turbofan jet engine.

\section{REFERENCES}

[1] Addo-Tenkorang, R., Helo, P., \& Kantola, J. (2016). Engineer-To-Order Product Development: A Communication Network Analysis for SupplyChain's Sustainable Competitive Advantage. In Supply Chain Strategies and the Engineer-to-Order Approach (pp. 43-59). IGI Global.

[2] Antoni, J., Griffaton, J., André, H., Avendaño-Valencia, L. D., Bonnardot, F., Cardona-Morales, O., ... \& Acuña, D. Q. (2017). Feedback on the Surveillance 8 challenge: Vibration-based diagnosis of 
a Safran aircraft engine. Mechanical Systems and Signal Processing, 97, 112-144.

[3] Araci, Z.C., Al-Ashaab, A. and Maksimovic, M. (2016) 'Knowledge Creation and Visualisation by Using Trade-off Curves to Enable Setbased Concurrent Engineering', The Electronic Journal of Knowledge Management, 14 (1), pp. 75-88.

[4] Araci, Z.C., Al-Ashaab, A., Lasisz, P.W., Flisiak, J.W., Mohd Maulana, M.I.I., Beg, N. and Rehman, A. (2017) 'Trade-off curves applications to support set-based design of a surface jet pump', Procedia CIRP, 60 (2017), pp. 356-361.

[5] Balli, O. (2017). Exergy modeling for evaluating sustainability level of a high bypass turbofan engine used on commercial aircrafts. Applied Thermal Engineering, 123, 138-155.

[6] Berton, J. J., Jones, S. M., Seidel, J. A., \& Huff, D. L. (2018). Noise predictions for a supersonic business jet using advanced takeoff procedures. The Aeronautical Journal, 122(1250), 556-571.

[7] Chandiramani, K.L.. (1974). Diffraction of Evanescent Waves; Applications to Aerodynamically Scattered Sound and Radiation from Unbaffled Plates. Journal of the Acoustical Society of America. 55. pp. 19-29.

[8] Cooper, R. G. (2016). Agile-Stage-Gate Hybrids: The Next Stage for Product Development Blending Agile and Stage-Gate methods can provide flexibility, speed, and improved communication in new-product development. Research-Technology Management, 59(1), 21-29.

[9] Gagliardi, P., Teti, L., \& Licitra, G. (2018). A statistical evaluation on flight operational characteristics affecting aircraft noise during takeoff. Applied acoustics, 134, 8-15.

[10] Gjestland, T., \& Granøien, I. L. (2016, August). Noise surveys at five Norwegian airports. In INTER-NOISE and NOISE-CON Congress and Conference Proceedings (Vol. 253, No. 8, pp. 201-207). Institute of Noise Control Engineering.

[11] Hebly, S. J., \& Visser, H. G. (2015). Advanced noise abatement departure procedures: custom-optimised departure profiles. The Aeronautical Journal, 119(1215), 647-661.

[12] Iglesias-Merchan, C., Diaz-Balteiro, L., \& Soliño, M. (2015). Transportation planning and quiet natural areas preservation: Aircraft overflights noise assessment in a National Park. Transportation Research Part D: Transport and Environment, 41, 1-12.

[13] Kennedy, B. M., Sobek, D. K. and Kennedy, M. N. (2014) 'Reducing rework by applying set-based practices early in the systems engineering process', Systems Engineering, 17(3), pp. 278-296.

[14] Kerga, E., Taisch, M., Terzi, S., Bessega, W. and Rosso, A. (2014) 'Setbased concurrent engineering innovation roadmap (SBCE IR): a case on Adiabatic Humidification', International Journal of Design Creativity and Innovation, 2(4), pp. 1-32.

[15] Khan, M. S., Al-Ashaab, A., Shehab, E., Haque, B., Ewers, P., Sorli, M. and Sopelana, A. (2013) 'Towards lean product and process development', International Journal of Computer Integrated Manufacturing, 26(12), pp. 1105-1116.

[16] Kopsch, F. (2016). The cost of aircraft noise-Does it differ from road noise? A meta-analysis. Journal of Air Transport Management, 57, 138142 .
[17] Kyprianidis, K. G., \& Dahlquist, E. (2017). On the trade-off between aviation NOx and energy efficiency. Applied Energy, 185, 1506-1516.

[18] Lawton, R. N., \& Fujiwara, D. (2016). Living with aircraft noise: Airport proximity, aviation noise and subjective wellbeing in England. Transportation Research Part D: Transport and Environment, 42, 104118.

[19] Lefèvre, M., Carlier, M. C., Champelovier, P., Lambert, J., Laumon, B., \& Evrard, A. S. (2017). Effects of aircraft noise exposure on saliva cortisol near airports in France. Occupational and environmental medicine, 74(8), 612-618.

[20] Morgan, J. M. and Liker, J. K. (2006) The Toyota product development system: integrating people, process, and technology. New York: Productivity Press.

[21] Nonaka, I., Kodama, M., Hirose, A. and Kohlbacher, F. (2014) 'Dynamic fractal organizations for promoting knowledge-based transformation - A new paradigm for organizational theory', European Management Journal, 32(1), pp. 137-146. doi: 10.1016/j.emj.2013.02.003.

[22] Rauch, E., Dallasega, P., \& Matt, D. T. (2016). The way from lean product development (LPD) to smart product development (SPD). Procedia CIRP, 50, 26-31.

[23] Saadon, S., \& Talib, A. A. (2016, October). An analytical study on the performance of the organic Rankine cycle for turbofan engine exhaust heat recovery. In IOP Conference Series: Materials Science and Engineering (Vol. 152, No. 1, p. 012011). IOP Publishing.

[24] Sandberg, M., Tyapin, I., Kokkolaras, M., Lundbladh, A., \& Isaksson, O. (2017). A knowledge-based master model approach exemplified with jet engine structural design. Computers in Industry, 85, 31-38.

[25] Sobek, D. K., Ward, A. C. and Liker, J. K. (1999) 'Toyota's principles of set-based concurrent engineering', Sloan management review, 40(2), pp. 67-84.

[26] Schuh, G., Gartzen, T., Soucy-Bouchard, S., \& Basse, F. (2017). Enabling agility in product development through an adaptive engineering change management. Procedia CIRP, 63, 342-347.

[27] Tortorella, G. L., Marodin, G. A., Fettermann, D. D. C., \& Fogliatto, F. S. (2016). Relationships between lean product development enablers and problems. International Journal of Production Research, 54(10), 28372855.

[28] Trojanek, R., Tanas, J., Raslanas, S., \& Banaitis, A. (2017). The impact of aircraft noise on housing prices in Poznan. Sustainability, 9(11), 2088.

[29] Tyagi, S., Choudhary, A., Cai, X., \& Yang, K. (2015). Value stream mapping to reduce the lead-time of a product development process. International journal of production economics, 160, 202-212.

[30] Wang, Z. and Wang, N. (2012) 'Knowledge sharing, innovation and firm performance', Expert Systems with Applications, 39(10), pp. 8899 8908. doi: 10.1016/j.eswa.2012.02.017.

[31] Ward, A. C. and Sobek, D. K. (2014) Lean product and process development. 2nd edn. Cambridge, MA, USA: Lean Enterprise Institute.

[32] Womack, J. (2006) 'A lesson to be learned', Manufacturing Engineer, 85(2), pp. 4-5. 